\section{Heberden's nodes and osteoarthrosis of the hip}

SIR, I have read the interesting report by McGoldrick and O'Brien studying the relation between the various patterns of osteoarthritis (OA) of the hip and Heberden's nodes. ${ }^{1}$ Their paper also challenges our earlier report, which found no significant association between osteoarthrosis of the weight bearing joints (hips and knees) and Heberden's nodes in a controlled study. ${ }^{2}$

My main criticism of the McGoldrick and O'Brien paper is that they do not compare like with like. The prevalence and severity of the nodes in their axillary, superomedial, and protrusion groups combined (representing primary $\mathrm{OA}$ ) is indeed higher than in the congenital dislocation of the hip, dysplasia, and superolateral groups combined (representing secondary $\mathrm{OA}$ ). On the other hand, the combined female to male ratio is $32 / 18$ among the probands in the first three groups and 15/22 among the probands in the last three groups. As is also pointed out by the authors this represents a clear difference in favour of women in the groups representing primary OA.

It is universally acknowledged that Heberden's nodes by themselves are more common among women, regardless of the presence of OA in other joints. Thus it would have been better if the authors had analysed their data by considering the prevalence of the nodes among the two genders separately in order to eliminate the sex bias.

Division of Rheumatology,

HASAN YAZICI

Department of Medicine,

Cerrahpaşa Medical Faculty,

University of Istanbul,

Turkey

\section{References}

1 McGoldrick F, O'Brien T. Osteoarthritis of the hip and Heberden's nodes. Ann Rheum Dis 1989; 48: 53-5.

2 Yazici H, Saville P, Salvati E A, Bohne W H O, Wilson P D. Primary osteoarthrosis of the knee or hip. JAMA 1975; 231: 1256-60.

SIR, I wish to make a number of comments in reply to the question posed by Dr Yazici on our paper entitled 'Osteoarthritis of the hip and Heberden's nodes'.' Dr Yazici feels that our population sample is based in favour of women, thereby distorting the data. I would like to make two points.

Our total population was composed of 44 men and 56 women, giving a male/female ratio of $1 / 1 \cdot 27$. This fits closely with publications throughout the world. Hoaglund et al quoted a population of $1 / 1 \cdot 29 .^{2}$ Our population sample was a consecutive number of patients attending for total hip replacement, in which no attempted bias was undertaken, therefore it can be reasonably said that the reflected the population of osteoarthritic patients requiring total hip replacement. If we look at our data allowing for the skew of $1 / 1.27$ there is still a greater number of womep showing primary osteoarthritis, with a male/female ratio of $1 / 1 \cdot 77$, whereas the reverse is the case for secondary arthritis, with a male/female ratio of $1 / 0 \cdot 65$. Even if we allow for the skew that may well exist in a populatio $\overline{ }$ sample by virtue of the greater number of women present it is clear that the ratio indicates a greater prevalence of women with primary osteoarthritis.

The second point $I$ wish to make is that if we were to extrapolate and compare an identical population of malef female patients with osteoarthritis, our data then would not reflect that of the population and would be skewed in favour of men. On that basis the ratios would then fall te almost even figures, which is not a reflection of the true picture.

St Mary's Orthopaedic Hospital, F McGOLDRIC@ Cappagh,

Finglas,

Dublin 11

\section{References}

1 McGoldrick F, O'Brien T. Osteoarthritis of the hip an Heberden's nodes. Ann Rheum Dis 1989; 48: 53-5.

2 Hoaglund F T, Shiba R, Newberg A H, Leung K Y. Diseases the hip. A comparative study of Japanese Oriental and American white patients. J Bone Joint Surg [Am] 1985; 6 1376-83.

3 Yazici H, Saville P, Salvati E A, Bohne W H O, Wilson P D Primary osteoarthritis of the knee or hip. JAMA 1975; 23P $1256-60$.

\section{Osteomalacia and coeliac disease presenting as isolated dactylitis}

SIR, We read with interest the case report 'Osteomalacio and coeliac disease presenting as isolated dactylitis' biv Jawad et al. ${ }^{1}$ We believe that the dactylitis was related to secondary parathyroid overactivity rather than a primaryo manifestation of osteomalacia.

We have a patient, an Asian vegetarian woman aged 46 years, who presented with pain and swelling in her right index and middle fingers. An $x$ ray examination wa suggestive of a dactylitis. Her investigations exclude tuberculosis, sarcoidosis, sickle cell disease, syphilis, and inflammatory arthritis.

Serum calcium was low $(2.06 \mathrm{mmol} / \mathrm{l})$, phosphate norm $(0.95 \mathrm{mmol} / \mathrm{l})$, alkaline phosphatase raised (212 IU//), and serum vitamin D very low ( $3 \mathrm{nmol} / \mathrm{l})$. Parathyroid hormone was $1.5 \mathrm{ng} / 1$ (normal up to 0.5 ). She was treated with 3000 $\mathrm{U}$ calciferol daily. Three months later her dactylitis hag 
settled and the biochemical abnormalities came back to normal, including parathyroid hormone of $0.48 \mathrm{ng} / \mathrm{l}$.

Our patient had dietary osteomalacia and secondary hyperparathyroidism which settled completely with calciferol treatment.

Department of Rheumatology,

A H SULTAN

St George's Hospital,

F E BRUCKNER

London SW17 0QT

\section{Reference}

1 Jawad A S M, Squire S B, Perry J D. Osteomalacia and coeliac disease presenting as isolated dactylitis. Ann Rheum Dis 1988; 47: 692-4.

SIR, The case report presented by Drs Sultan and Bruckner concluding that the dactylitis seen in their patient was a manifestation of secondary hyperparathyroidism is in keeping with conclusions we published previously. ${ }^{1}$

We pointed out that the radiological bone changes in our patient's hand were confined to the middle phalanx, and although they may well have been caused directly by the osteomalacia, it seemed more likely that they were a manifestation of secondary hyperparathyroidism. Clearly the finding of a raised parathyroid hormone is not unexpected and does not prove that the radiological changes were due to hyperparathyroidism, particularly as in our case the histology was non-specific, though tetracycline labelling was not performed.

Department of Rheumatology,

The London Hospital,

Whitechapel,

London E1 1BB

\section{Reference}

1 Jawad A S M, Squire S B, Perry J D. Osteomalacia and coeliac disease presenting as isolated dactylitis. Ann Rheum Dis 1988; 47: $692-4$.

\section{Inhibition of neutrophil myeloperoxidase by rabbit anti- (human myeloperoxidase)}

SIR, In the paper by Nurcombe and Edwards published in the Annals ${ }^{1}$ the authors claim to have shown inhibition of fluid phase neutrophil myeloperoxidase by the IgG fraction of an anti-myeloperoxidase antibody in a chemiluminescence system. But incredibly for such a reputable scientific journal they have been allowed to present their data (Fig. 5) without any reference to the effect of normal rabbit (control) IgG on fluid phase myeloperoxidase in the same system. Even if it had had no effect, this should have been mentioned. We have been using a similar system to evaluate the effect of antibodies to myeloperoxidase on the activity of the fluid phase enzyme, and there is undoubtedly considerable protein quenching by normal immunoglobulin (with apparent inhibition) of the chemiluminescence generated by fluid phase neutrophil myeloperoxidase, compared with activity in the absence of normal IgG. This must be taken into consideration in the interpretation of any 'inhibition' occurring in the presence of anti-myeloperoxidase IgG.

Regional Dept of Immunology,

R A THOMPSON

East Birmingham Hospital, S S LEE

Bordesley Green East,

Birmingham B9 5ST

\section{Reference}

1 Nurcombe H L, Edwards S W. Role of myeloperoxidase in intracellular and extracellular chemiluminescence of neutrophils. Ann Rheum Dis 1989; 48: 56-62.

SIR, Drs Thompson and Lee comment on the fact that in Fig. 5 (and 6) of our recent paper 'Role of myeloperoxidase in intracellular and extracellular chemiluminescence of neutrophils' ${ }^{11}$ we did not state the effects of equivalent amounts of non-immune IgG on this system. In such experiments we routinely measure the effects of nonimmune $\operatorname{IgG}^{23}$ as some types of chemiluminescence are susceptible to non-specific quenching by soluble proteins. The problem of non-specific protein quenching by antibodies is greatly reduced when IgG fractions are purified from high titre antisera. In our experiments such nonspecific quenching of extracellular chemiluminescence by equivalent amounts of non-immune IgG was only $5-10 \%$ of that observed by our anti-(myeloperoxidase) IgG and hence the effects noted in Figs 5 and 6 were due to specific inhibition of myeloperoxidase.

Dept of Biochemistry, University of Liverpool, STEVEN W EDWARDS PO Box 147,

Liverpool L69 3BX

\section{References}

1 Nurcombe $\mathrm{H} \mathrm{L}$, Edwards S W. Role of myeloperoxidase in intracellular and extracellular chemiluminescence of neutrophils. Ann Rheum Dis 1989; 48: 56-62.

2 Edwards S W, Swan T F. Regulation of superoxide generation of myeloperoxidase during the respiratory burst of human neutrophils. Biochem J 1986; 237: 601-4.

3 Edwards S W. Luminol- and lucigenin-dependent chemiluminescence of neutrophils: role of degranulation. J Clin Lab Immunol 1987; 22: 35-9. 